\section{Coronary vasospasm induced by subcutaneous sumatriptan}

Drs F Willett, N Curzen, ADAms, and M Armitage (Royal Bournemouth Hospital) write: Sumatriptan is a serotonin-1 $\left(5 \mathrm{HT}_{1}\right)$ agonist which binds receptors in cranial blood vessels causing vasoconstriction. It is used to treat migraine and cluster headache..$^{1-3}$

A 47 year old man with a history of cluster headaches, for which he was taking methysergide and ergotamine, was admitted in May 1991 com plaining of chest pain. The pain unrelated to exertion, had been present intermittently for five months, and there were no other cardiovascular or gastrointestinal symptoms. He had no history of ischaemic heart disease but smoked 30 cigarettes daily. Physical examination was normal. Serial electrocardiograms and cardiac enzyme values remained normal. A Bruce protocol exercise test was performed before discharge, in which he completed 12 minutes 55 seconds with no symptoms or electrocardiographic changes.

He was readmitted on 15 December 1991 complaining of chest pain at rest. For 10 days before admission he had experienced cluster headaches, from which ergotamine spray and methysergide had provided no relief. On 11 December sumatriptan was therefore prescribed in addition to his other medication. On both the first two occasions he had administered a subcutaneous dose of sumatriptan he had experienced severe chest pain within minutes. After admission serial electrocardiograms and cardiac enzyme concentrations were again normal, and his medication was stopped.

A trial was performed in which a standard $6 \mathrm{mg}$ subcutaneous dose of sumatriptan was administered during electrocardiographic monitoring. Four minutes after injection he developed chest pain and two minutes later there was widespread ST elevation in the inferior and
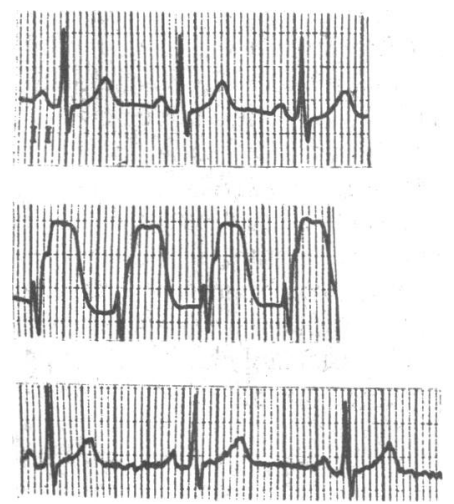

Electrocardiogram lead II before and after subcutaneous sumatriptan: top, before injection; middle, 5 min $37 \mathrm{~s}$ after injec tion; bottom, 22 min after injection anterolateral territory (figure). There was no response to sublingual glyceryl trinitrate. By 22 minutes after the injection all pain had subsided and the electrocardiogram had returned to normal. The creatin kinase-MB level a few hours later was normal.

The data sheet states that sumatriptan should not be given intravenously because of the potential for coronary vasospasm or subcutaneously in patients with ischaemic heart disease. A recent editoria in the $B M \mathcal{F}$ claimed that no serious cardiovascular adverse effects had been published in relation to subcutaneous sumatriptan. ${ }^{3}$ The Committee on Safety of Medicines has had one other report of coronary vasospasm in association with sumatriptan given subcutaneously. This case shows that subcutaneous sumatriptan can precipitate coronary vasospasm.

1 The Sumatriptan Cluster Headache Study Group. Treatment of cluster headaches with sumatriptan. N Engl f Med 1991;325:322-6.

The Subcutaneous Sumatriptan Internation Study Group. Treatment of migraine attacks with sumatriptan. N Engl f Med 1991;325: 316-21.

3 Pearce JMS. Sumatriptan in migraine. $B M \mathcal{F}$ 1991;303:1491

\section{Acute adrenal insufficiency associated with high dose inhaled steroids}

Drs J Wong and P Black (Auckland Hospital, Auckland 1, New Zealand) write: High dose inhaled steroids have been associated with dose dependent adrenocortical suppression' but not so far with acute adrena insufficiency. We describe a patien who experienced symptomatic adrenal insufficiency when his dose of inhaled steroid was reduced.

A 38 year old man with allergic bronchopulmonary aspergillosis was being treated with high dose inhaled budesonide delivered from a Turbohaler. Four months before we saw him his dose of budesonide had been increased from $1.6 \mathrm{mg} /$ day to $4.8 \mathrm{mg} / \mathrm{day}$ and then two weeks later to $6.4 \mathrm{mg} /$ day. His asthma improved and after a fortnight the dose was reduced to $3 \cdot 2 \mathrm{mg} /$ day. He continued on this dose for six weeks before a further reduction was made to $2.4 \mathrm{mg} /$ day. Within days he complained of lethargy, malaise, nausea, vomiting, and dizziness. When we saw him three weeks later he was still taking $2.4 \mathrm{mg} /$ day but his symptoms were improving. At the time his budesonide was increased from 1.6 to $4.8 \mathrm{mg} /$ day he had just completed a six week course of oral prednisone. He had not, however, received any oral corticosteroids in the four months before we saw him or at any other time in the previous year. $\mathrm{He}$ was also being treated with a beclomethasone diproprionate nasal spray in a dose of $200 \mu \mathrm{g} / \mathrm{day}$.

Clinical examination showed nothing abnormal. Plasma cortisol concentration measured at 9 am was very low at $22 \mathrm{nmol} / \mathrm{l}$ (normal 220-770), as were dehydroepiandrosterone sulphate concentrations $(1 \cdot 1 \mu \mathrm{mol} / \mathrm{l}$; normal $2 \cdot 8-9 \cdot 6)$ and 24 hour urinary free cortisol $(18 \mathrm{nmol} /$ day; normal 100-330). His response to a short tetracosactrin stimulation test performed a few days later was subnormal, with the plasma cortisol concentration rising from $50 \mathrm{nmol} / \mathrm{l}$ to only $174 \mathrm{nmol} / \mathrm{l}$. Plasma aldosterone concentration was normal. The patient continued to take budesonide $2.4 \mathrm{mg} /$ day, and a further short tetracosactrin test performed a month later showed a normal increase in the plasma cortisol concentration (from $204 \mathrm{nmol} / 1$ to $490 \mathrm{nmol} / \mathrm{l}$ )

Inhaled budesonide is not usually given in doses higher than $1.6 \mathrm{mg}$ / day. This case suggests that acute adrenal insufficiency can develop with doses much higher than this if the dose is then reduced too rapidly. Rather than exceed a dose of budesonide of $1 \cdot 6-2 \cdot 4 \mathrm{mg} /$ day or a dose of beclomethasone diproprionate of 2 to $3 \mathrm{mg} /$ day it may be more appropriate to give the patient oral corticosteroids as well as inhaled steroids.

1 Gordon $\mathrm{ACH}$, McDonald CF, Thomson SA, Frame MH, Pottage A, Crompton GK. Dose of inhaled budesonide required to produce clinical suppression of plasma cortisol. Eur $\mathcal{F}$ Respir Dis 1987;71:10-4.

\section{Cardiac arrest associated with flumazenil}

Drs Yeshayahu Katz, Monther Boulos, Pierre Singer, and Beno Rosenberg (Rambam Medical Center, POB 9602, 31096 Haifa, Israel) write: Flumazenil is used for reversing short or long term benzodiazepine sedation. We describe here an association between flumazenil and ventricular fibrillation.

A 60 year old man was admitted to the coronary care unit because of extensive acute anterior wall myocardial infarction. $\mathrm{He}$ had no history of cardiac disease, well controlled hypertension being his only risk factor for coronary artery disease. Thrombolytic treatment was not administered owing to a long delay between onset of symptoms and admission. On the second day the patient developed pulmonary oedema which required mechanical ventilation, supported by pancuronium bromide for muscle relaxation and morphine and diazepam for sedation. Because of haemodynamic instability a Swan-Ganz catheter was inserted. During the

insertion the patient developed sustained ventricular tachycardia which was treated by direct curren electric shock. On the fifth day his cardiorespiratory status stabilised. The patient began to wake and resisted ventilation. $\mathrm{He}$ was still drowsy and uncooperative, however, behaviour which was attributed to the effect of the diazepam. To facilitate his weaning from the respirato flumazenil was administered via slow intravenous injection. When cumulative dose of $0.4 \mathrm{mg}$ had been reached the patient suddenly developed sustained ventricula achycardia, followed by ventricula fibrillation and asystole. He died 20 minutes later, despite continued attempts at resuscitation.

Flumazenil administered to volunteers did not alter haemodynamic values.' No significan haemodynamic changes occurred when it was given to non-cardiac patients sedated with benzodiazepines $^{2}$ or when it was used to reverse benzodiazepine intoxication. ${ }^{3}$ In patients with moderate to severe coronary heart disease or valve esions who were sedated with diazepam for cardiac catheterisation and coronary angiography flumazeni caused no change in invasively measured or calculated cardiac values over the sedated state. ${ }^{3}$ By contrast, it induced moderate change in blood pressure after cardiac surgery ${ }^{4}$ and in some cases precipitated ventricular arrhythmia.

Until recently, no deaths in connection with flumazenil had been reported. In the past year, however, two deaths occurred after administration of flumazenil to patients intoxicated with a cocktail of drugs (including benzodiazepines). ${ }^{67}$ The time course in these cases accorded better with a wearing off of the reversal effect (and recurrence of intoxication) rather than a direct effect of flumazenil. In contrast, the close proximity of events in our report indicates a causal association between flumazenil and the fatal arrhythmia.

1 Rouiller M, Forster A, Gemperle M. Assess ment of the efficacy and tolerance of benzodiazepine antagonist (Ro 15-1788). Ann Fr Anesth Reanim 1987;6:1-6.

Geller E, Niv D, Nevo Y, Leykin Y, Sorkin P, Rudick V. Early clinical experience in reversing benzodiazepine sedation with flumazenil after short procedures. Resuscitation 1988;16(suppl):S49-56.

3 Geller E, Niv D, Weinbrum A, Silbiger A Halpern $P$, Sorkin $P$. The use of flumazenil in the treatment of 34 intoxicated patients. Resuscitation 1988;16(suppl):S57-62.

4 Louis M, Forster A, Suter PM, Gemperle M. Clinical and hemodynamic effects of specific benzodiazepine antagonist $(R$ 15-1788) after open heart surgery [abstract. Anesthesiology 1984;61:A61.

5 Short TG, Maling T, Galletly DC. Ventricula arrhythmia precipitated by flumazenil. $B M \mathcal{F}$ 1988;29: 1070-1.

6 Burr W, Sandham P, Judd A. Death afte flumazenil. $B M \mathcal{F}$ 1989;298:1713.

$\mathrm{Lim}$ AG. Death after flumazenil. $B M \mathcal{J}$ 